\title{
Carlos Alfaro*
}

Universidad Nacional de Rosario (Argentina)

arnolfo29@yahoo.com.ar

\section{La noción de «alma bella» en el pensamiento de Hölderlin de Hegel}

\section{The notion of «beautiful soul» in the thoughts of Hölderlin and Hegel}

Resumen: Varios comentaristas sostienen que el pensamiento de Friedrich Hölderlin es un ejemplo de la concepción hegeliana de «alma bella». En el presente artículo, se demostrará que la figura del Espíritu antes mencionada tiene fundamentos ontológicos que difieren del contenido de la noción de «alma bella» concebida por Hölderlin.

Palabras clave: Hegel, Hölderlin, alma bella, yo, autoconciencia, deber, subjetividad, objetividad.
Abstract: Many scholars maintain that Friedrich Hölderlin's thought is an example of the Hegelian notion of «beautiful soul». In this article, I will demonstrate that the aforementioned shape of Spirithas ontological grounds which are different to the content of Hölderlin's notion of «beautiful soul».

Keywords: Hegel, Hölderlin, beautiful soul, I, selfconsciousness, duty, subjectivity, objectivity.

\footnotetext{
* Profesor, Doctor en Filosofía. Adscripto a la cátedra «Problemática Política» en la carrera de Filosofía de la Universidad de Humanidades y Artes de la Universidad Nacional de Rosario. Entre sus publicaciones, se destaca el artículo Diferencias entre la concepción de «virtud» en el pensamiento de Shaftesbury y la concepción de «alma bella» en la filosofía de Hegel. En Cuaderno de Materiales 28, 2016, pp. 5-16. ISSN: 1139-4382. Línea de Investigación: Idealismo alemán.
} 
Hegel expone su concepción de «alma bella» en la Fenomenología del Espiritu. El filósofo alemán sostiene que la principal característica de la mencionada figura del Espíritu es la igualdad del yo consigo mismo, pues la autoconciencia y la conciencia del deber poseen el mismo contenido. La paridad entre ambos momentos es representada por la fórmula «yo = yo». Esta igualdad es intuida inmediatamente por el «alma bella», y se presenta como su único contenido. Semejante definición pareciera una referencia a la filosofía fichteana, que postula la igualdad del Yo absoluto consigo mismo. Sin embargo, Hegel afirma que la perspectiva propia del «alma bella» fue expuesta por un círculo de continuadores de la filosofía de Fichte, y no por el mencionado filósofo. ${ }^{1}$ Según el pensador suabo, la filosofía fichteana postula una actividad que se dirige a la reconciliación de los opuestos (Yo y No-Yo) en el infinito y que da paso al anhelo de realización. Pero los discípulos a quienes se refiere Hegel confunden el Yo absoluto con el yo psicofísico. Es decir, ellos consideran que el sujeto trascendental y la conciencia empírica son uno y lo mismo. De este modo, el fundamento absoluto de toda la realidad es la conciencia empírica.

Un primer grupo de continuadores del sistema fichteano son los ironistas, con Friedrich Schlegel como su representante más conocido. Los ironistas postulan al Yo psicofísico como lo absoluto e incondicionado, negando la objetividad del No-Yo. El Yo es la negación absoluta, radical, sin determinación ulterior, del No-Yo. El segundo grupo de continuadores sostiene una filosofía en la que la subjetividad pone en duda la objetividad de todo pensamiento. Como consecuencia de ello, la subjetividad no logra realizarse objetivamente y busca subsumirse bajo lo positivo en un intento por aferrarse a algo concreto. El tercer grupo de continuadores del sistema de la Doctrina de la Ciencia concibió una filosofía de la subjetividad, que consiste en una carencia, una actividad hacia lo concreto, y permanece así tan sólo un anhelo (Sehnsucht). Esta subjetividad permanece anhelante y se extingue en sí. Es una subjetividad que es pura interioridad, pues permanece en sus pensamientos. Hegel señala a Novalis como el representante más ilustre de este círculo de pensadores y considera que sus escritos representan el anhelo de un alma bella. ${ }^{2}$

\footnotetext{
Cfr. Georg Wilhelm Friedrich Hegel: Vorlesungen über die Geschichte der Philosophie. Tomo III. Decimoquinto tomo de Georg Wilhelm Friedrich Hegel's Werke: Vollständige Ausgabe durch einen Verein von Freuden des Verewigten. Duncker y Humblot, Berlín, 1836, pp. 641-646.

2 Cfr. Georg Wilhelm Friedrich Hegel: Vorlesungen über die Geschichte der Philosophie. Tomo III, pp. $644-645$. Existe un cuarto grupo de continuadores de la filosofía de Fichte. Ellos postulan la subjetividad del arbitrio, la ignorancia. Su exponente es Jakob Fries.
} 
Hegel se refiere a este tercer grupo en los siguientes términos: «La extravagancia de la subjetividad deviene frecuentemente locura; ella permanece en el pensamiento, es atrapada en el torbellino del entendimiento reflexivo, que es siempre negativo ante sí mismo». ${ }^{3}$ Emanuel Hirsch considera que la mención de la locura es una referencia tácita al trágico destino de Hölderlin. ${ }^{4}$ Hans Schmeer sostiene la misma hipótesis. ${ }^{5}$ El poeta alemán, íntimo amigo de Hegel, padecía de esquizofrenia. El filósofo alemán nunca incluyó explícitamente la obra de su amigo en el concierto de ejemplos que caían bajo la definición de «alma bella». Sin embargo, la omisión de su nombre puede entenderse como una muestra de respeto a quien fuera objeto de su afecto personal. A simple vista, el pensamiento de Hölderlin guarda cierto parecido con la concepción crítica de «alma bella» que Hegel expone en sus escritos. Más específicamente, los personajes principales de la novela Hyperion poseen rasgos atribuibles a la mencionada figura del Espíritu.

La obra mencionada es una novela epistolar, compuesta de cuatro libros, que narra las peripecias de Hyperion. ${ }^{6}$ Su padre le había aconsejado que viajara a Smyrna para que conociera la cultura de los pueblos más avanzados. Pero su estadía en Smyrna resultaría de lo más desilusionante. Desde entonces, estaría siempre solo. Hyperion conocería a Alabanda. Este último estaba comprometido con el resurgimiento de Grecia, su madre patria. Hyperion se uniría a su causa. Pero la relación entre Alabanda e Hyperion se vería dañada porque el primero detestaba la idea de ejercer poder sobre la población recurriendo a la sociedad con hombres y métodos indignos. Hyperion se dirige con un amigo llamado Notara a Kalaurea. El protagonista conocería a su amada Diotima en ese lugar. Ella escucharía a Hyperion mientras narraba su vida, y le diría que él buscaba dioses, no hombres, y que sufría por no aprehender la totalidad. Diotima le sugiere a Hyperion que viaje a Alemania, Italia, Francia, por unos tres años, para que educara al pueblo a su regreso, pues él había nacido para grandes cosas.

3 Georg Wilhelm Friedrich Hegel: Vorlesungen über die Geschichte der Philosophie. Tomo III, pp. 644-645: «Die Extravaganz der Subjektivität wird häufig Verrücktheit; bleibt sie im Gedanken, so ist sie im Wirbel des reflektirenden Verstandes befangen, der immer gegen sich negative ist». [La traducción es del autor del artículo].

4 Cfr. Emanuel Hirsch: Die Beisetzung der Romantiker in Hegels Phänomenologie. En: Hans Friedrich FuldA y Dieter Henrich (eds.): Materialen zu Hegels «Phänomenologie des Geistes». Suhrkamp Verlag, Frankfurt am Main, 1973, pp. 245-275.

5 Cfr. Hans Schmeer: Der Begriff der «schönen Seele» besonders bei Wieland und in der deutschen Literarur des 18. Jabrhunderts. En: Germanische Studien, Heft 44. Kraus Reprint Limited, Nedeln/Liechtenstein, 1967, pp. 72-73.

${ }^{6}$ Cfr. Friedrich Hölderlin: Hyperion oder der Eremit in Griecheland. Tomo I de Friedrich Hölderlin's Sämtliche Werke. J.G. Gottascher Verlag, Stuttgart y Tubinga, 1846. Cfr. Friedrich Hölderlin: Hiperión o "El eremita en Grecia». Traducción: Jesús Muñárriz. Ediciones Hiperion, SL., España, 1988. 
Alabanda le envía una carta a Hyperion. En la misma le comunica que los rusos avanzaban con una flota hacia el archipiélago y que buscarían la libertad de los griegos. Alabanda instiga a Hyperion a unirse con él en mar abierto y luchar contra los turcos. Diotima lee la carta de Alabanda y le dice a Hyperion que la guerra lo destruiría. Finalmente, le pide que deje de lado sus ideales de juventud. Pero Hyperion decide unirse a Alabanda y su tropa en la península del Peloponeso. Lamentablemente, ellos son derrotados por los turcos y sus aliados. Luego de la derrota, Hyperion y Alabanda se unen a la flota rusa de mar, abandonando Grecia. En la batalla naval, los rusos hicieron arder la flota turca. Hyperion le escribe a Diotima y le comunica que él ya no pensaba volver a Grecia. Diotima le escribe a Hyperion y le comunica su sorpresa, pues pensaba que él había fallecido en la batalla. Sin embargo, le dice que él ya no le pertenece. Finalmente, Diotima anuncia su muerte a Hyperion. Le dice que no se sienta mal, pues su destino ha sido tener una vida bella, coronada por una muerte de igual belleza. Hyperion se exilia en Alemania y vuelve a sus reflexiones sobre la naturaleza y lo bello, donde se encuentra la eternidad y Diotima continúa con vida.

Bernhard Paha afirma que el protagonista de la novela Hyperion tiene ciertos rasgos atribuibles a la concepción hegeliana de «alma bella». Por un lado, la liberación de Grecia -símbolo del origen divino de la cultura Occidental-, es el ideal irrealizable de una vuelta a la «Edad de Oro» de la humanidad. La supuesta «Edad de Oro» es similar a la fantasía de una infancia en la cual el hombre vive en armonía con la naturaleza, sin ser consciente de su propia mortalidad. Es decir, el mismo origen soñado por Novalis cuando reclamaba la unificación del Cristianismo. ${ }^{7}$ Por otro lado, Hyperion no logra más que soñar con este reino: una fantasía, elaborada mentalmente, pero imposible de ser concretado por la acción humana. Es el universal abstracto, vacío, que Hegel le endilgaba al «alma bella» cuando criticaba a la misma. Según el comentarista, el protagonista de la novela no está dispuesto a arriesgar la pureza de su alma para concretar su objetivo. Paha considera que Hyperion se transforma en un «corazón duro» que se contenta con criticar sin piedad la vida del pueblo alemán. ${ }^{8}$

Finalmente, Pinkard remarca la pertenencia de Hölderlin al círculo de discípulos de Fichte, ya que el primero había asistido a las clases que el 
mencionado filósofo había impartido en la Universidad de Jena en 1794. El comentarista considera que tanto Novalis como Hölderlin buscan una definición de la unidad inmediata preexistente a la identidad del yo consigo mismo. Pues la conciencia de sí implica que el yo se pone a sí mismo como objeto. Por consiguiente, la división sujeto-objeto subsiste en la fórmula «yo = yo». La unidad preexistente sólo puede ser intuida intelectualmente, ya que no existe mediación reflexiva alguna que pueda dar cuenta de ella. Su «inmediatez» implica que no puede ser expresada, sino tan sólo «mostrada» por medio de metáforas en la obra de arte. Hölderlin considera que la unidad original es el «ser absoluto», que puede ser intuido en la belleza natural o en la poesía. Novalis considera que dicha unidad es el «Yo universal», en el cual no hay distinción entre el sujeto observante y el objeto observado. ${ }^{9}$

Sin embargo, en el presente artículo se sostiene que Hegel no considera que la obra de Hölderlin sea un caso representativo de la filosofía del «alma bella». La interpretación que el poeta alemán hace del sistema filosófico fichteano no resulta en la confusión entre el Yo absoluto y el yo psicofísico. Por este motivo, Hölderlin no concibe el yo psicofísico como lo absoluto e incondicionado. La ausencia de una subjetividad que afirme su interioridad como la totalidad de la realidad ética es clave para comprender por qué la obra del poeta alemán no puede ser tenida en cuenta como un caso ejemplar de la concepción hegeliana de «alma bella». La demostración de la presente hipótesis exige, en primer lugar, la exposición de la noción de «alma bella» en el pensamiento de Hölderlin. En segundo lugar, es necesario desarrollar sintéticamente la concepción hegeliana de «alma bella». Finalmente, es imprescindible una conclusión que subraye las diferencias entre ambas perspectivas.

\section{La noción de «alma bella» en el pensamiento de Hölderlin}

Tal como se mencionó anteriormente, Hölderlin había abrevado en la filosofía fichteana. Fichte sostiene que el Yo absoluto es el fundamento incondicionado de toda conciencia. La esencia del Yo como incondicionado es su propia actividad (su propio poner-se a sí mismo). Por este motivo, el Yo es al mismo tiempo lo activo y lo producido por esta misma actividad.

Cfr. Terry PInKard: German philosophy 1760-1860: The legacy of Idealism. Cambridge University Press, New York, 2002, pp. 137-148. 
De esta manera, aquello cuya esencia simplemente consiste en ponerse a sí mismo como siendo es el yo como sujeto absoluto. Del mismo modo que él se pone, es; y entonces el yo es necesariamente y absolutamente para el yo. El Yo, en este caso, es definido por la proposición «Yo $=$ Yo». ${ }^{10} \mathrm{El}$ poeta alemán criticaría a Fichte en Urteil und Sein (1795). ${ }^{11}$ En el citado manuscrito, Hölderlin sostiene que la identidad del yo consigo mismo no es una unidad, pues tal identificación supone la distinción entre sujeto y objeto:

Si yo digo: yo soy yo, entonces el sujeto (yo) y el objeto (yo) no están tan unidos, de tal manera que ninguna separación pueda ser percibida, sin dañar la esencia de éste que tiene que ser separado; al contrario, el yo sólo es posible por medio de esta separación del yo por el yo. ¿Cómo puedo decir «yo» sin autoconciencia? ¿Pero cómo es posible la autoconciencia? Precisamente porque yo me opongo a mí mismo, me separo de mí mismo, pero a pesar de esta separación me reconozco en los opuestos como esto mismo. ¿Pero en qué medida como esto mismo? Yo puedo, así que debo preguntar; pues el yo se opone a sí mismo en otra perspectiva. Por consiguiente, la identidad no es ninguna unión de objeto y sujeto que tenga lugar sin más, y así la identidad no es $=$ al ser absoluto. ${ }^{12}$

Cuando un individuo enuncia «yo», afirma implícitamente la proposición «yo soy yo». A pesar de su aparente simplicidad, la mencionada proposición no puede ser la unidad original. Pues la misma supone la distinción entre los dos términos de la identidad del yo consigo mismo: el primer «yo» es el sujeto, y el segundo «yo» es el objeto. La operación de identificación entre ambos es la homogeneización de elementos heterogéneos. La propia conciencia de sí no puede ser el punto de partida como unidad original. Esta última debe ser indivisa. Por este motivo, Hölderlin rechaza la concepción del Yo absoluto como principio de toda filosofía.

${ }^{10}$ Cfr. Gottlieb Johann Fichte: Doctrina de la Ciencia. Traducción e introducción de Juan Cruz. Aguilar Argentina S.A., Buenos Aires, 1975, pp. 13-20.

${ }^{11}$ Cfr. Friedrich Hölderlin: Urteil und Sein. Tomo IV de Friedrich Hölderlin: Sämtliche Werke. Hölderlin-Archiv der Württembergischen Landesbibliothek, Stuttgart, 1962, pp. 226-228.

12 Friedrich Hölderlin:UrteilundSein, p. 227: «Wenn ich sage: Ich bin Ich, so ist das Subjekt (Ich) und das Objekt (Ich) nicht so vereiniget, daß gar keineTrennung vorgenommen werden kann, ohne, das Wesen desjenigen, was getrennt warden soll, zu verletzen; im Gegenteil das Ich ist nur durch diese Trennung des Ichs vom Ich möglich. Wie kann ich sagen: Ich! Ohne Selbstbewußtsein? Wie ist aber Selbstbewußtsein möglich? Dadurch daß ich mich mir selbst entgegensetze, mich von mir selbst trenne, aber ungeachtet dieser Trennung mich im entgegengesetzten als dasselbe erkenne. Aber in wie ferne als dasselbe? Ich kann, ich muß so fragen; denn in einer andern Rücksicht ist es sich entgegengesetzt Also ist die Identität keine Vereinigung des Objekts und Subjekts, die schlechthin stattfände, also ist die Identität nicht = dem absoluten Sein». [La traducción es del autor del artículo]. 
Para Hölderlin, el ser es el origen de la totalidad. Este es una unidad a la cual intenta retornar la conciencia. Pero el retorno al ser original es un proceso sin fin. Por este motivo, el ideal y la certeza de la unidad tienen que hacérsenos presentes por otro camino que aquél de la conciencia de sí. ${ }^{13}$ En Hyperion el ser se manifiesta en la belleza. ${ }^{14}$ Esta última es definida como la totalidad que anhelan los hombres. ${ }^{15}$ Tal como se desprende de una carta de Hyperion a su amigo Bellarmin:

¡Oh vosotros, los que buscáis lo más elevado y lo mejor en la profundidad del saber, en el tumulto del comercio, en la oscuridad del pasado, en el laberinto del futuro, en las tumbas o más arriba de las estrellas! ¿Sabéis su nombre?, ¿el nombre de lo que es uno y todo?

Su nombre es belleza. ${ }^{16}$

Del párrafo citado se desprende que la belleza es el fin último de la teoría y la praxis. Pues es lo más elevado a lo que puede aspirar quien busca la sabiduría o quien se entrega a la acción. La belleza se presenta como la totalidad armónica, o lo que es uno y todo. ${ }^{17} \mathrm{El}$ vínculo estrecho entre la belleza y el ser se presenta en la poesía (Dichtung), ya que en dicha expresión artística habita el ser infinito y divino. El lenguaje poético no se circunscribe a la finitud, sino que se refiere a la infinitud que lo finito presupone. El ser infinito es intuido como bello por el individuo que intenta percibirlo. Sin embargo, Hölderlin reconoce que el ser no puede ser intuido ni concebido como tal. La filosofía busca dar cuenta del ser, pero no logra reconciliar los

${ }^{13}$ Cfr. Dieter Henrich: Presupuestos históricos del sistema hegeliano. En: Dieter Henrich: Hegel en su contexto. Traducción de Jorge Aurelio Díaz. Monte Ávila Editores, Caracas, 1990, pp. 37-77.

${ }^{14}$ Cfr. Josef Chytri: The Aesthetic State: A quest in modern German thought. University of California Press, Londres, 1989, pp. 122-123, 127-131.

15 Cfr. Dieter Henrich: Hegel y Hölderlin. En: Dieter Henrich: Hegel en su contexto, pp. 11-35.

${ }^{16}$ Friedrich Hölderlin: Hiperión o "El eremita en Grecia», p. 29. Friedrich HöLderLin: Hyperion oder der Eremit in Griecheland, p. 48: «O ihr, die ihr das Höchste und Beste sucht, in der Tiefe des Wissens, imGetümmel des Handelns, im Dunkel des Vergangenheit, im Labyrinthe der Zukunft, in den Gräbern oder über den Sternen! Wißt ihr seinen Namen? Den Namen daß, das Einsist und Alles? Sein Name ist Schönheit».

${ }_{17}$ Cfr. Friedrich Hölderlin: Hyperion oder der Eremit in Griecheland, p. 76. Hyperion sostiene que la proposición de Heráclito -que el uno está escindido en sí mismo-, define la esencia de la belleza. Pues esta últimaes inmanente a cada ente finito del mundo. 
opuestos. ${ }^{18} \mathrm{El}$ pensamiento filosófico sólo puede tener su origen en la poesía, pues la unidad de los irreconciliables -la tarea de la filosofía-, supone la presencia del ser absoluto que se presenta en la dimensión poética. La filosofía no puede tener su origen en el entendimiento, pues este último se limita a la esfera de los entes finitos. Tampoco puede originarse en la razón, ya que esta última es el impulso constante y ciego por reunificar y distinguir. Pero la razón es guiada por un factor externo; a saber, el principio divino de lo uno en sí mismo distinguido, o ideal de belleza, que le revela por qué y para qué busca la reconciliación y la distinción. Es decir, la razón, por intermedio del ideal divino de belleza, busca dar el orden de la totalidad armónica al mundo de los entes finitos. Esta «luz» divina que emana sobre la razón, no proviene de la razón misma, sino de la poesía. ${ }^{19}$

Hölderlin, a través de su personaje Hyperion, sostiene que la belleza se encuentra en la naturaleza: «Feliz naturaleza! No sé lo que me pasa cuando alzo los ojos ante tu belleza, pero en las lágrimas que lloro ante ti, la bienamada de las bienamadas, hay toda la alegría del cielo». ${ }^{20}$ La naturaleza es entendida justamente como la totalidad orgánica en la que lo individual y diverso cobra sentido como parte de un todo vivo y coherente. Como la naturaleza es una totalidad, no sufre determinaciones exteriores: ella se determina a sí misma. Tampoco es condicionada por ningún factor que no sea ella misma. Por este motivo, la naturaleza es lo absoluto. Es un movimiento infinito en el cual ni el tiempo ni la muerte tienen lugar. Pues ambas determinaciones sólo pueden

18 Friedrich Hölderlin: Hiperión o «El eremita en Grecia», pp. 43-4: «¿Qué tiene que ver la filosofía?” me respondió, “¿qué tiene que ver la fría excelsitud de esa ciencia, con la poesía?”. "La poesía”, dije seguro de lo que decía, "es el principio y el fin de esa ciencia. Como Minerva de la cabeza de Júpiter mana esa ciencia de la poesía de un ser infinitamente divino. Y así confluye al fin también en ello lo que hay de incompatible en la misteriosa fuente de la poesía”». Friedrich HöLDERLin: Hyperion oder der Eremit in Griecheland, p. 75: «Was hat die Philosophie, erwiedert” er, was hat die kalte Erhabenheit dieser Wissenschaft mit Dichtung zu thun? Die Dichtung, sagt' ich, meiner Sache gewiß, ist der Anfang und das Ende dieser Wissenschaft. Wie Minerva aus Jupiters Haupt, entspringt sie aus der Dichtung eines unendlichen, göttlichen Seyns. Und so läuft am End' auch wieder in ihr das Unvereinbare in der geheimniß vollen Quelle der Dichtung zusammen».

19 Friedrich Hölderlin: Hiperión o «El eremita en Grecia», p. 45: «De la pura inteligencia no ha surgido ninguna filosofía, pues la filosofíano es más que una ciega exigencia de un progreso nunca demasiado resolutivo en el arte de unir y de diferenciar una determinada sustancia. Pero, en cambio, si la razón que aspira a elevarse es iluminada

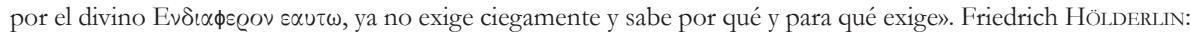
Hyperion oder der Eremit in Griecheland, p. 77: «Aus bloßem Verstande kömmt keine Philosophie, den Philosophie ist mehr, denn nur die beschränkte Erkenntniß des Vorhandnen. Aus bloßer Vernunft kömmt keine Philosophie, denn Philosophie ist mehr, denn blinde Forderung eines nie zu endigen den Fortschritts in Vereinigung und

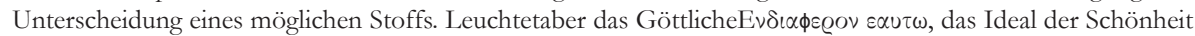
der strebendenVernunft, so fordert sie nicht blind, und weiß warum,wozu sie fordert».

${ }^{20}$ Friedrich Hölderlin: Hiperión o «El eremita en Grecia», p. 7. Friedrich Hölderlin: Hyperion oder der Eremit in Griecheland, p. 6: «O selige Natur! Ich weiß nicht, wie mir geschiehet, wenn ich mein Auge erhebe vor deiner Schöne, aber alle Lust des Himmels ist in den Thränen, die ich weine vor dir, der Geliebte vor der Geliebten». 
afectar a los entes finitos. Aquél que la contempla, se olvida de sí mismo para participar de su eternidad. El olvido de sí implica la anulación de la conciencia; con ello se da la renuncia al ansia de dominación por la cual el hombre intenta someter a la naturaleza y a sus congéneres. Si subsistiera el deseo de someter a los otros -y a lo otro-, el hombre se encontraría a sí mismo excluido de la infinitud: sería consciente de sí mismo en tanto fuera consciente de su finitud, y no podría acceder a la totalidad orgánica infinita de la naturaleza. ${ }^{21}$

El individuo autoconsciente es consciente de su propia finitud, porque se reconoce como una subjetividad que contempla la naturaleza que ella misma ha objetivado. La objetivación de la naturaleza lo distancia de la eternidad a la que accede a través del sentimiento. La capacidad de reflexionar, lejos de ser una virtud del hombre, representa su «caída» del estado paradisíaco en el cual el ser humano participaba de lo absoluto. ${ }^{22}$ Lacontemplación de la belleza natural permite desligarnos momentáneamente de nosotros mismos y de la conciencia de nuestra propia finitud, para acceder al reino celestial del cual hemos sido expulsados. ${ }^{23}$

La belleza eterna es lo absoluto, que los hombres conocen como el ámbito de lo divino. En un comienzo, los dioses y los hombres eran uno y lo mismo, pues no había conciencia de sí. Cuando el ser humano adquirió conciencia de sí, se apartó de lo incondicionado y se diferenció de lo divino. Los dioses del hombre son la representación que él tiene de sí mismo cuando era partícipe de este reino celestial. Hölderlin sostiene, a través del protagonista de la novela, que el impulso artístico proviene de la necesidad que tiene el ser humano de contemplar su propia belleza; es decir, de observarse a sí mismo como lo divino. ${ }^{24}$ En la bella obra de arte se manifiesta el origen divino del hombre, pues esta no es un objeto ante el cual el ser humano pueda oponerse como una subjetividad finita, sino el reflejo de su propia naturaleza infinita.

Pero sólo los sabios son capaces de reconocer que el hombre participa de la belleza infinita y universal. Los demás individuos, el vulgo, experimentan su propia naturaleza divina como una esencia extraña a ellos mismos: es algo exterior y ajeno a sus existencias. Los seres humanos crean imágenes que reflejan su propia condición. En vez de asumir que estas últimas son sus propias creaciones, las elevan al status de dioses y les rinden culto. ${ }^{25} \mathrm{La}$

\footnotetext{
${ }^{21}$ Cfr. Friedrich Hölderlin: Hyperion oder der Eremit in Griecheland, pp. 6-7.

22 Cfr. Friedrich HöLderLIN: Hyperion oder der Eremit in Griecheland, p.7.

${ }^{23}$ Cfr. Friedrich Hölderlin: Hyperion oder der Eremit in Griecheland, pp. 53 y 148.

${ }^{24}$ Cfr. Friedrich Hölderlin: Hyperion oder der Eremit in Griecheland, pp. 73-74.

${ }^{25}$ Cfr. Friedrich Hölderlin: Hyperion oder der Eremit in Griecheland, p. 74.
} 
inmortalidad de los dioses es la negación de la mortalidad que padece la conciencia individual.

La alienación que padece el ser humano, al extrañarse de su propia naturaleza divina, no se vincula específicamente a la historia universal de la humanidad en general. Hölderlin no se concentra tan sólo en el tránsito de la naturaleza a la civilización que había experimentado la especie humana. El autor de Hyperion también se refiere a la transformación que sufre el individuo desde su infancia hasta la edad adulta. Cuando el hombre es un niño, no tiene conciencia de la muerte. Por este motivo, es inmortal. El niño no es consciente de la ley ni del destino; por consiguiente, no padece la opresión de estos factores. La falta de comprensión de la ley no le permite diferenciar aún el bien del mal. La ignorancia acerca de su destino lo libera del sufrimiento que le provoca la conciencia de su futuro. El infante es libre de todas las ataduras que llegan con la adultez. Hölderlin sostiene, a través de Hyperion, que el niño es entonces una criatura inocente, que no está descontenta consigo misma. La ausencia de descontento evidencia la falta del malestar que sienten los adultos cuando piensan en lo que son y lo que desean ser. La niñez es la absoluta coincidencia entre lo que es y lo que debe ser. Por este motivo, el niño es bello. Tal manifestación de belleza sólo es explicable si se comprende que el infante es una criatura divina. ${ }^{26}$

Con el surgimiento de la autoconciencia culmina la infancia. La distancia y el extrañamiento con respecto a la niñez se manifiestan en la incapacidad de conceptualizarla. La conciencia de sí, lejos de significar un progreso en la existencia del hombre, representa un retroceso. Esta «falsa conciencia» le impide el retorno al reino divino de la belleza. El estado de alienación resultante de esta transformación se muestra claramente en el temor a la muerte. Este último es infundado, pues la mortalidad es sólo una apariencia: el ser humano confunde el fin de su autoconciencia con la aniquilación de su existencia.

Sin embargo, la naturaleza divina del hombre es inmortal y este puede llegar a aprehenderla en el amor. Pues al enamorarse, no objetiva al otro. ${ }^{27}$ Hölderlin comprende que el amor implica la des-objetivación del otro. La relación entre el sujeto y el objeto es asimétrica y presupone siempre el dominio del primero sobre el segundo. En el plano de las relaciones intersubjetivas, el individuo se

\footnotetext{
${ }^{26}$ Cfr. Friedrich Hölderlin: Hyperion oder der Eremit in Griecheland, p. 8.

${ }^{27}$ Cfr. Friedrich Hölderlin: Hyperion oder der Eremit in Griecheland, pp. 65-70. Según Diotima, el amor que siente hacia Hyperion, y que es correspondido, les revela a ambos su inmortalidad.
} 
«objetiva» a sí mismo y a su prójimo e intenta someterse y someterlo. Pero el amante no percibe al amado como un mero objeto. Los amantes se consideran bellos recíprocamente. Es decir, se reconocen como partícipes de la belleza. Como ya se había señalado, quien participa de la belleza tiene una naturaleza divina. Por consiguiente, el amante percibe que su amado participa de la eternidad y plenitud de la belleza. Hölderlin no considera que el amor implique la reflexión de la subjetividad del amante en la subjetividad del amado. El sujeto se opone al objeto, de tal manera que este último lo limita y condiciona. La subjetividad está necesariamente constituida como finita. La reflexión de una subjetividad en otra no puede mostrarle su inconmensurabilidad, ya que lo inconmensurable es infinito y la subjetividad es una instancia finita. Para el autor de Hyperion, la des-objetivación del amado presupone la insuficiencia de la subjetividad autoconsciente. Si el individuo se concibe a sí mismo y a los demás como objetos, los amantes asumen que sus autoconciencias no logran dar cuenta de la experiencia amorosa. Según la perspectiva de Hölderlin, el alma bella es el amante que ha asumido su finitud como una apariencia. El amante comprende entonces que su verdadera naturaleza es infinita. En su novela, Hyperion y Diotima se definen recíprocamente como almas bellas. ${ }^{28}$ El vínculo amoroso que los une, les permite concebirse de esa manera. ${ }^{29}$ Hyperion no teme arriesgar su vida, consciente que su temor es infundado: la muerte no implica la aniquilación de su existencia inmortal, sino el fin de su autoconciencia.

\section{La concepción de «alma bella» en la filosofía de Georg Wilhelm Friedrich Hegel}

La característica esencial de la figura del Espíritu conocida como «alma bella» es la igualdad del yo consigo mismo. Hegel lo afirma en su Fenomenología delEspiritu: «la autoconciencia ha retornado ahora a su refugio más íntimo, ante el que desaparece toda exterioridad como tal, a la intuición del yo $=$ yo, donde

\footnotetext{
${ }^{28}$ Cfr. Friedrich Hölderlin: Hyperion oder der Eremit in Griecheland, pp. 88-9.

${ }^{29}$ Cfr. Friedrich HölderLin: Hyperion oder der Eremit in Griecheland, p. 112.
} 
este yo es toda esencialidad y toda existencia». ${ }^{30} \mathrm{La}$ igualdad del yo consigo mismo presupone una distinción previa, pues la operación mencionada sólo es posible en tanto existan dos términos que pueden ser igualados. O sea, el alma bella se ha desdoblado previamente en dos instancias: la conciencia del deber y la autoconciencia. La primera se caracteriza porque es la intuición de la universalidad del deber. Este no es intuido como una esencia de la realidad ética exterior, sino como una determinación propia. Es decir, el contenido del deber es puesto por el alma bella. Pero si el contenido del deber es puesto por el alma bella, la conciencia del deber intuye su propio contenido: se intuye a sí misma. La autoconciencia es el momento de reconocimiento de la intuición de sí como intuición de la universalidad del deber. Luego, la autoconciencia del alma bella reconoce que ella se impone su propia ley moral: ella se condiciona a sí misma. O sea, el alma bella asume que no es condicionada por factor externo alguno; o, lo que es lo mismo, que es incondicionada. Pero lo incondicionado es lo absoluto o divino. Por consiguiente, la autoconciencia del alma bella asume que ella es lo divino que se intuye a sí mismo.

Puede observarse que el vínculo entre ambas instancias se constituye como una igualdad: la autoconciencia posee el mismo contenido que la conciencia del deber. Sin embargo, la autoconciencia y la conciencia del deber no comparten la misma determinación formal. En primer lugar, la autoconciencia es una determinación individual. Es decir, esta es una singularidad afectada por factores particulares. En segundo lugar, la conciencia del deber es una determinación universal. O sea, esta es la intuición de la esencia universal contenida en ella misma. El vínculo establecido entre la autoconciencia y la conciencia del deber es una identidad abstracta. Pues no contempla las determinaciones del individuo y el universal intuido. Semejante relación sólo es posible si la autoconciencia permanece abstraída de las particularidades del mundo exterior, ya que el yo individual se objetiva en la acción. Es decir, la subjetividad del yo individual se transforma eventualmente en un resultado objetivo, mediante la acción concreta en la exterioridad. La objetividad conquistada es una existencia finita, determinada en un espacio y tiempo concretos. Una autoconciencia que asume su finitud no puede identificarse con la conciencia del deber, pues la universalidad abstracta de la ley moral

\footnotetext{
${ }^{30}$ Georg Wilhelm Friedrich Hegel: Fenomenología del Espiritu. Traducción de Wenceslao Roces con la colaboración de Ricardo Guerra. Primera edición en español en 1966. Octava reimpresión, 1991. Fondo de Cultura Económica, México DF, 1966, p. 383. Georg Wilhelm Friedrich Hegel: Phänomenologie des Geistes. Quinto tomo de Georg Wilhelm Friedrich Hegel: Sämtliche Werke: neue keritische Ausgabe. Sexta edición. Felix Meiner Verlag, Hamburg, 1952, p. 461: «Wir sehen hiemit hier das Selbstbewußtsein in sein Innerstes zurückgegangen, dem alle Äußerlichkeit als solche verschwindet, -in die Anschauung des Ich = Ich, worin dieses Ich alle Wesenheit und Dasein ist».
} 
no se adecúa a las particularidades de una individualidad concreta. Por este motivo, la autoconciencia del alma bella no se involucra en ninguna actividad y permanece inmaculada. ${ }^{31}$

El alma bella se mantiene en la igualdad consigo misma. Su supuesta infinitud descansa en la intuición del deber como su fundamento esencial. Ella se percibe como la autoconciencia que ha sido puesta por el deber ser universal. Cuando enuncia que es consciente de sí, sostiene que es consciente de su ser-puesto por la ley que ha concebido como universal. El individuo debe actuar en consonancia con su ley interior. Si cometiera un acto que no se ajustara a lo establecido por esta última, se intuiría alienada del universal. Con su perseverancia en esta identidad abstracta, desconoce su «otredad». Es decir, afirma que sólo actúa en conformidad con el deber. Al aseverarlo, niega que sus juicios sean motivados por su particular vanidad moral más que por respeto a la universalidad de la ley. Su negativa al reconocimiento de los móviles patológicos que impulsan sus decisiones implica el rechazo a su propia determinación individual concreta. Su individualidad es una abstracción de los atributos particulares que la constituyen como individuo. La expresión más clara de esta situación es la censura al momento de actuar: el alma bella se limita a juzgar a las conciencias que actúan. Su abstención con respecto a todo aquello que rebase el plano de lo meramente discursivo también está fundada en la negación de su individualidad concreta. Si el alma bella actuara, su acción estaría limitada por las condiciones espaciotemporales, históricas, culturales en las que todo acto se encuentra condicionado. Más aún, el impulso interior que la conduciría a la acción no sería el respeto a la objetividad del deber, sino el sentimiento personal de satisfacción por la exteriorización de su propia interioridad.

El alma bella afirma su universalidad. Pero la misma instancia de afirmación representa su exclusión del mundo exterior, ya que ella sólo puede sostener esta abstracción en tanto se abstenga de actuar. La inactividad no sólo implica la ausencia de objetivación de su subjetividad, sino también el rechazo de la intersubjetividad. ${ }^{32}$ Pues la pasividad del alma bella también implica la

\footnotetext{
31 Cfr. Charles Taylor: Hegel. New York, Cambridge University Press, New York, 1975, pp. 148-96. El alma bella considera que la virtud es la renuncia a lo particular. Esto implica la supresión de la existencia, pues la misma es experimentada como el mal.

32 Cfr. Terry Pinkard: What is a 'shape of the spirit'? En: Dean Moyar y Michael Quante (eds.): Hegel's Phenomenology of Spirit - A critical guide. Cambridge University Press, New York, 2008, pp. 112-129. Desde el punto de vista de los demás, la concepción de deber que sostiene el alma bella es una arbitrariedad. La supuesta belleza de las acciones del alma bella no puede ser comprobada por nadie más que ella misma. Por este motivo, el alma bella cae en el aislamiento.
} 
repulsión de la comunidad con otros individuos. Paradójicamente, el alma bella se ha singularizado: es una subjetividad sin contenido concreto alguno, cuya única cualidad es el rechazo a la universalidad de la sustancia espiritual. ${ }^{33}$ La bella subjetividad se rebela contra el Espíritu. Su rebelión es el intento de sostener la igualdad consigo misma como la realidad desde la cual juzga a los demás. Pero el Espíritu tiene la potestad de la realidad efectiva. Los individuos actúan en el marco del Espíritu universal que los rebasa y comprende. El Espíritu abarca y trasciende a los humanos y los vínculos que sostienen entre sí: los miembros de una sociedad comparten el universal como aquello que tienen en común. Un hombre puede exponer su particular perspectiva del mundo y de las relaciones humanas para actuar con arreglo a sus preceptos, pero no puede imponer los mismos a los demás, y menos aún esperar que los acontecimientos se desarrollen según lo que haya proyectado. ${ }^{34}$

\section{Conclusión}

Tal pareciera que la noción de «alma bella» expuesta por Hölderlin comparte ciertas similitudes con la figura del Espíritu hegeliana. Hyperion asume que la finitud de su autoconciencia es la apariencia tras la cual se oculta la infinitud de su existencia divina. El protagonista de la novela logra abstraerse momentáneamente de la conciencia de sí mismo mediante la percepción de la belleza natural. Pues la contemplación de lo bello natural implica la intuición de la totalidad armónica que se determina a sí misma, y de la cual Hyperion es parte constitutiva. Del mismo modo, la figura del Espíritu concebida por Hegel se escinde en dos momentos: autoconciencia y conciencia del deber. La primera es una individualidad finita. La autoconciencia reconoce que la conciencia del deber es la intuición de su propia interioridad como la totalidad de la realidad ética que se determina a sí misma.

\footnotetext{
33 Cfr. Otto Pöggeler: Hegels Kritike der Romantik. H. Bouvier u. Co. Verlag, Bonn, 1956, pp. 94-137. El temor del alma bella a individualizarse en la acción le impide obrar. Paradójicamente, esta situación no le permite realizar su pensamiento y formar parte del Espíritu. Por este motivo, el alma bella no logra trascender su propia particularidad. Se escinde así de la sustancia espiritual.

34 Cfr. Heinz WeLL: Die «schöne Seele» und ibre 'sittliche Wirklichkeit': Überlegungen zum Verbältnis von Kunst und Staat bei Hegel. Verlag Peter Lang GmbH, Frankfurt am Main, 1986, pp. 79-91. La esencia de la conciencia del alma bella es el predicado del yo. La inmediatez de la conciencia se traduce en una «realización» por medio del lenguaje de la convicción, y no por medio de la acción.
} 
Sin embargo, las similitudes entre ambos planteos ocultan la diferencia esencial entre las dos perspectivas. Para el «alma bella» hegeliana, la identidad entre la subjetividad finita y el Yo absoluto es el fundamento de la totalidad armónica. Según Hölderlin, la identidad de la subjetividad finita con el Yo absoluto no es la unidad originaria, sino que presupone una diferencia entre el «Yo» afirmado como sujeto y el «Yo» afirmado como objeto. Por este motivo, el fundamento último de la totalidad es el ser absoluto. Para el autor de Urteil und Sein, la subjetividad que se concibe a sí misma como el yo absoluto, no sólo no es el fundamento de la totalidad armónica, sino que tampoco es capaz de percibir lo incondicionado. La autoconciencia, al tomarse a sí misma como el fundamento absoluto de la totalidad armónica, concibe erróneamente lo finito como si fuera infinito. La postura de Hölderlin lo aleja de la exposición crítica que hiciera Hegel acerca del «alma bella». Según el filósofo alemán, la mencionada figura del Espíritu se caracteriza porque toda su esencia se reduce a la identidad del yo consigo mismo. Pero la concepción de alma bella que presenta el poeta alemán no se sustenta en la identificación de la subjetividad consigo misma, sino en el reconocimiento individual de su participación en el ser absoluto.

\section{Bibliografía}

Chytry, Josef: The Aesthetic State: A quest in modern German thought. University of California Press, Londres, 1989.

Fichte, Gottlieb Johann: Doctrina de la Ciencia. Traducción e introducción de Juan Cruz. Aguilar Argentina S.A. de Ediciones, Buenos Aires, 1975.

Hegel, Georg Wilhelm Friedrich: Fenomenología del Espiritu. Traducción de Wenceslao Roces con la colaboración de Ricardo Guerra. Primera edición en español en 1966. Octava reimpresión, 1991. Fondo de Cultura Económica, México DF, 1966.

Hegel, Georg Wilhelm Friedrich: Phänomenologie des Geistes. Quinto tomo de Georg Wilhelm Friedrich Hegel: Sämtliche Werke: neue kritische Ausgabe. Sexta edición. Felix Meiner Verlag, Hamburg, 1952.

Hegel, Georg Wilhelm Friedrich: Vorlesungen über die Geschichte der Philosophie. Tomo III. Decimoquinto tomo de Georg Wilhelm Friedrich Hegel's Werke: 
Vollständige Ausgabe durch einen Verein von Freuden des Verewigten. Editado por Duncker y Humblot, Berlín, 1836.

Heinrich, Dieter: Hegel en su contexto. Traducción de Jorge Aurelio Díaz. Monte Ávila Editores, Caracas, 1990.

Hirsch, Emanuel: Die Beisetzung der Romantiker in HegelsPhänomenologie. En: Hans Friedrich Fulda y Dieter Henrich (eds.): Materialen zu Hegels «Phänomenologie des Geistes». Suhrkamp Verlag, Frankfurt am Main, 1973.

HölderLIn, Friedrich, Urteil und Sein. Tomo IV de Friedrich Hölderlin: Sämtliche Werke. Hölderlin-Archiv der Württembergischen Landesbibliothek, Stuttgart, 1962.

Hölderlin, Friedrich: Hiperión o «El eremita en Grecia». Traducción: Jesús Muñárriz. Ediciones Hiperion, SL., España, 1988.

HöLDERLIN, Friedrich: Hyperion oder der Eremit in Griecheland. Tomo I de Friedrich Hölderlin's Sämtliche Werke.J.G. Gottascher Verlag, Stuttgart y Tubinga, 1846.

Novalis: Die Christenheit oder Europa. Primera parte de Novalis Schriften. G. Reimer, Berlín, 1826.

PAHA, Bernhard: Die schöne Seele Hegels und die Literatur der Frühromantik: Studienarbeit. GRIN Verlag, Alemania, 1992.

Pinkard, Terry: German philosophy 1760-1860: The legacy of Idealism. Cambridge University Press, New York, 2002.

Pinkard, Terry: What is a 'shape of the spirit'? En: Dean Moyar y Michael Quante (eds.): Hegel's Phenomenology of Spirit - A critical guide. Cambridge University Press, New York, 2008.

Pöggeler, Otto: Hegels Kritik der Romantik. H. Bouvier u. Co. Verlag, Bonn, 1956.

Schmeer, Hans: Der Begriff der «schönen Seele» besonders bei Wieland und in der deutschen Literarur des 18. Jabrhunderts. En: Germanische Studien, Heft 44. Kraus Reprint Limited, Nedeln/Liechtenstein, 1967.

TAYLor, Charles: Hegel. New York, Cambridge University Press, New York, 1975.

Well, Heinz: Die «schöne Seele» und ibre «sittliche Wirklichkeit»: Überlegungen zum Verbältnis von Kunst und Staat bei Hegel. Verlag Peter Lang GmbH, Frankfurt am Main, 1986. 